\title{
Research on Evaluation Model of the Effective EFL Teaching in the Era of Informatization
}

\author{
Jinzhu Zhang \\ School of Foreign Languages, Tianjin Polytechnic University, Tianjin, China
}

\begin{abstract}
The world is changing with a remarkable speed with the advancement of the informatization, which has revolutionized many fields. EFL teaching in China enjoys great priority. While in the era of IT, traditional teaching mode can no longer satisfy the needs of the globalization and Chinese society. In order to improve the classroom efficiency, the first thing the author believes should be done is the reform of the traditional evaluation system of EFL classroom teaching. In this paper, the author proposes a new framework to evaluate the college EFL classroom teaching in the context of information age, hoping to contribute to the improvement of teaching efficiency at college EFL classroom.
\end{abstract}

Index Terms-EFL teaching, inforamtization, effective classroom teaching, evaluation framework, new framework

\section{INTRODUCTION}

Informatization is an irreversible trend of the present world, which has brought huge opportunities as well as great challenges to every aspect of human life. The upsurge of informatization has revolutionized the way of school education and knowledge acquisition. Traditional teaching model cannot meet the demands in the new era. More and more educators begin to doubt and reflect the traditional conception of effective teaching. EFL teaching is no exception. The construction of information facilities and the use of information resources in educational context have changed the traditional classroom teaching form and the roles of teachers, and have contributed to a new cognitive mode of teaching. Therefore, what is effective classroom teaching, how to carry out effective classroom teaching, and how to evaluate effective classroom teaching, all of which have intrigued the researchers and college EFL teachers as well, have gradually become the focus of attention and research by many experts and scholars in recent years. This paper puts forward some suggestions for the research on the effectiveness of College EFL teaching under the educational information technology, which is an indispensable supplement to the effective classroom teaching. And based on the research of effective classroom teaching, this paper tries to build a scientific, reasonable and applicable teaching evaluation framework with the purpose to facilitate the language teaching and inspire more interesting discussions on the issue.

\section{LITERATURE REVIEW}

\section{A. Problems of EFL Teaching in China}

Classroom teaching plays an important role in the process of foreign language learning. Classroom is a place for students to accept high-quality language input. Teachers should use classroom teaching to arouse students' learning enthusiasm, help students discover and use the language rules and guide students to learn independently by interacting with their classmates and teachers and practicing language skills through extensive extracurricular exercises of reading, listening and speaking (Wen, 2014).

"during the past 30 years of reform and opening up, the reform of foreign language education in China has advanced by leaps and bounds", and its basic characteristics can be summed up as: "continuous heating-up, rapid development, and great achievements"(DHEMOE, 2007). Many experts and scholars in EFL education have found that there are many problems in foreign language teaching in China, especially in College EFL classroom teaching. "Problems still exist" (Hu, 2014). For a long time, 'time-consuming and inefficient' and 'dumb and Deaf English' and other problems have not been thoroughly resolved yet (Dai, 2008). Dai (2008) generalizes the problems existing in four aspects: the macro level of EFL educational policy; the teaching and learning model of EFL; talents' training of EFL; the targets of EFL discipline construction.

Shu (2014) explicitly points out that there are 5 obvious problems in Chinese foreign language educational system: The weak theoretical research of foreign language classroom teaching; Lack of scientific, reasonable and effective evaluation standard of classroom teaching; the vague teaching goal; Teacher-centered; Lack of innovation in teaching process; the ineffective unity between Classroom teaching and extracurricular learning, etc (Shu, 2014). More scholars and college EFL teachers have expressed their dissatisfaction towards the EFL education in China based on their qualitative and quantitative research or teaching practice. Some researchers (Wang, 2010; Wang, 2012; Xia, 2002) in China carry out the massive needs analysis investigation among six major categories of the subjects, they are: teachers 
(including teaching administrators), graduates (including employees), employers, social residents and other non-human elements (such as teaching materials). Most of the research indicates that people involved in EFL teaching and learning are not satisfied with EFL teaching and their EFL proficiency. And the research proposed the EFL policy-making based on the needs analysis and other operational suggestions.

In this paper, the author narrows down the problems and focuses on the problems in EFL classroom teaching evaluation with the expectation to assess the teachers' instruction more scientifically in the era of information technology, thus motivating teachers to fully engage in EFL classroom teaching and improving the effectiveness of EFL teaching in China.

\section{B. Effective EFL Teaching in the Era of IT}

Research outside China on CALL (computer-assisted language learning) can be basically divided into three levels. The first level is the CALL research based on the computer technology, such as the EuroCALL program of E.U Which specializes in the study of CALL(Michael, 2010); Secondly, the researchers, like Mark Warschauer (2000) \& Michael Levy(1997), focus on language acquisition and language teaching with the educational technology as a teaching tool to assist the teaching of listening, speaking, reading and writing; The third level of the research is to study the network-assisted language teaching and second language acquisition with network technology as its core. For example, the integration of network technology, classroom teaching methods and learning methods. Niki Lambropoulos (2005) studies the learner-centered online learning design. Michael Thomas (2009) studies the problems of second language learning based on Web2.0.

At present, there are few theories and practices on the effectiveness of college EFL teaching under the context of China's educational information technology. However, these achievements are very useful as the reference to the research in China. The research on the IT-assisted instruction in Chinese context has become a hot topic for scholars. From the year of 2000 to 2017, 25 monographs have been published in this field, which cover a wide range of topics, such as: the modern educational technology and foreign language teaching; the methods and applications of computer-assisted second language research; computer-assisted language teaching; modern language teaching: theory and practice, online learning and development; Technology in the linguistic interpretation of foreign language teaching, foreign language multimedia teaching and other topics(Fang, 2017). All these studies mainly take College EFL as the research objects. More national publishing houses presently are actively involved in the platform developments of the college EFL teaching materials, such as the Higher Education Press, etc. But one obvious problem of those platforms is lack of the effective empirical research on the efficiency of these resources, and more emphasis is placed on the integration of technology, curriculum design and development.

\section{Characteristics of Effective College EFL Teaching Based on IT}

The researchers(Shu, 2015; Wen, 2014; Dai, 2009) believe that the basic characteristics of effective teaching should include the following aspects: to embody the basic purpose of promoting human development (the first is the basic goal of subject teaching; the second is the development objective of subjectivity); Scientific and reasonable teaching content (firstly, teachers should correctly understand and creatively use teaching materials; secondly, the educational factors of teaching content should be carefully excavated; thirdly, attention should be paid to the practicality of teaching contents); Teachers' teaching ability which refers to the ability to monitor, regulate classroom teaching and practice; a good command of language proficiency.

In addition, the characteristics of course instruction of college EFL itself determine the features of effective college EFL teaching. Under the educational information technology, many variables, such as: the curriculum design for teachers and students; the content of teaching and the teaching environment of using English, may have a huge impact on the effective teaching of college EFL (Shu, 2010). Other implicit variables, such as the teachers' views on language teaching and teachers' information proficiency, teachers' view on educational technology, Sense of responsibility, cognitive style, emotional state, personality, teachers' international cultural experience, education and training, teaching efficacy, teaching ability, students' information literacy, learning strategies and cognitive strategies based on technical environment and learners' ability to use language, etc (Fang 2017). All these elements listed above are the factors that affect the effective college EFL teaching. Therefore, it becomes quite challenging for researchers to design a single model which embraces all those variables inside and produce a convincing and scientific conclusion. However, it is a common belief among the scholars (Fang, 2017) that an informative, diagnostic and summative teaching evaluation is an important means and method to test the effectiveness of college EFL teaching in the context of educational information technology.

\section{Evaluation of Effective Classroom EFL Teaching}

Evaluation has always been an essential procedure in foreign language curriculum construction. regardless of the syllogism of curriculum construction proposed by Nunan (1988), the coherence model of curriculum construction proposed by Johnson (1989) or the definition of four steps in curriculum design from Richards (1990) and the dynamic model of curriculum construction on the basis of reviewing the models above put forward by Graves (2008), all the research above unanimously regard teaching evaluation as the necessary procedure of the curriculum construction. The modern theory of testing which is used to test the effect of curriculum construction holds that the 
classroom teaching evaluation should not only provide an accurate and reliable measurement method, but also have a good feedback effect on teaching (Bachman,1996) and should be beneficial to both sides involved (Bachman 1996). Comparatively speaking, it can be seen from the literature review above that the concept of teaching evaluation in the research of foreign scholars has a wide range of categories, which examines many elements in teaching, and even extends to the field of social education situation.

The evaluation of foreign language teaching has always been a hot topic in the field of foreign language teaching in China. Shu (2010) defines five functions of foreign language classroom teaching, in other words, the basic criteria of effective classroom teaching. They are: arousing students' interest in learning; providing appropriate learning resources; assisting students to solve their learning difficulties; training students' learning strategies; providing students with opportunities to demonstrate their learning results (Shu, 2014). Based on the discussion on the five functions above, he discusses the importance of evaluation to classroom teaching and provides a guiding framework for the evaluation of foreign language classroom teaching. It is worth noting that he emphasizes the connection between classroom teaching and extracurricular learning in the evaluation dimension for many times. That is, classroom teaching should be the guide of extracurricular learning, which is the extension of classroom learning (Shu, 2010). Besides, Classroom teaching evaluation is not only an evaluation of the teaching effect of a single class, there are also other relevant evaluation criteria with the focus on a whole stage or period of classroom teaching activities and their effects (Fang, 2017). Classroom teaching evaluation should be concerned with whether the objectives of the teaching can clearly reflect the curriculum requirements, whether the needs of students are fully satisfied in teaching process, whether the classroom teaching can be well connected with extracurricular Learning, whether the foreign language classroom teaching can reasonably balance the relationship between knowledge interpretation and language practice, Whether classroom activities are conducive to cultivating students' ability of inquiry learning and autonomous learning(Shu, 2014; Fang, 2017; Chen, 2014).

Due to the long-term impact of examination-oriented education, learning assessment has always been the main standard and sometimes the only standard to measure the classroom teaching evaluation (Liu 2012). That is to say, the teaching effect is measured by the results of students' summative evaluation. The introduction of formative evaluation theory makes the teaching management authority begin to attach importance to the change and development of students and teaching activity in the whole process, particularly The effect on the results of the learning evaluation produced by the teaching activities in the whole teaching process (Shu, 2014 ).

In the latest issue of 2017 Guidelines of College English Teaching, the direct participants of the teaching evaluation of College English include the managing directors of college EFL teaching, the teachers and students (DHE-MOE, 2017), which to some extent has broadened the subject category of the evaluation and has embodied the emphasis on the other education subjects from the policy-making in the context of college EFL teaching. However the follow-up guidelines just develop the basic requirements and guidelines for "college English curriculum evaluation" and "College Students' English proficiency test", and advocates a comprehensive evaluation system that is based on the "university-based evaluation and other diversified evaluation" and "college English examinations at all levels" and many other kinds of testing methods. This concept to some extent is a just a follow-up of the traditional idea that teaching evaluation is mainly determined by the tests of students (Fang 2017). The evaluation of effective classroom teaching is not given enough attention although the students' evaluation of teaching is mentioned in some teaching research (Mei, 2013;Zhao, 2014; Shao, 2015).

And what the author has to point out is the discussion on the effective classroom teaching from the other dimensions is quite limited, especially in the context of informationization, although the topics, such as the rationality, effectiveness, the factors and the teaching evaluation index system, are fully discussed in the research.

\section{E. The Framework of Teaching Evaluation}

The tradition of valuing the effectiveness of teaching outside China has a long history. Harris et al (2014) reported that Florida spent $\$ 45$ million to evaluate the effectiveness of teaching, many measures were adopted and lots of variables were examined. And the results of the research were employed on the decision of teachers' career, such as the appointment, promotion and dismissal of the faculty. But research shows that these different evaluation methods not only affect the rewards and punishments of specific teachers in the short term, but also affect the quality of whole faculty In the long run. The most representative scholar of all in the United States is Danielson (1996), who constructed the teaching effectiveness evaluation framework based on the Constructivism teaching concept and related empirical research.

The Danielson's research team in 2013 published their latest version of the teaching evaluation framework, which covers 22 observation perspectives with 76 microscopic levels. The four-point scale was employed-unsatisfactory, average, good and excellent. In his framework, all aspects of teaching activities are evaluated, and each level of the evaluation is entitled with detailed descriptions, which mainly include three layers, they are: the general description corresponding to its levels; the key features and possible representations. This may ensure the clarification and objectivity of the evaluation perspectives and dimensions to the utmost. The subjective randomness of evaluation is avoided. Since 1996, the proposed teaching evaluation framework has been widely accepted internationally by the participants involved in teaching practice (Chen 2014). Its four-dimensional observation dimension and 22 observational perspectives are shown in figure 1: 


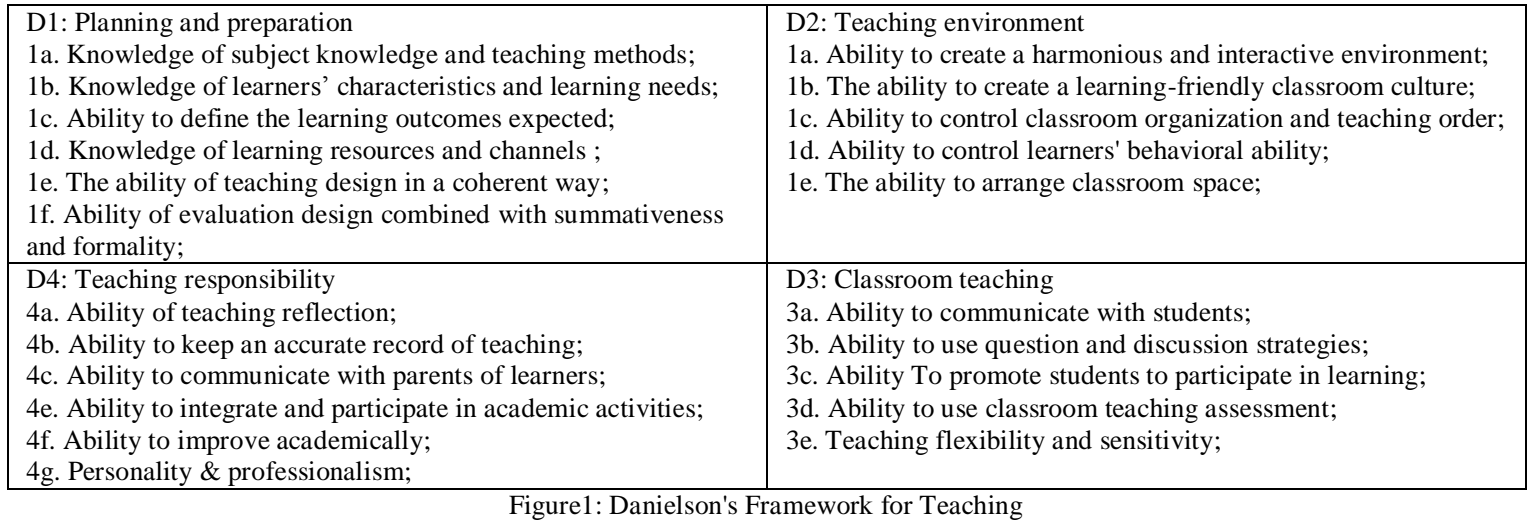

As is shown in table 1, the Danielson's teaching evaluation framework refines the four dimensions of teaching evaluation and clarifies the observational perspective of each dimension. Providing a large number of descriptive words to ensure the consistency, accuracy and objectivity of the evaluation, the assessors can ensure the reliability and validity of teaching evaluation.

Garrett Sternberg (2015) mentions that the FFT (Danielson's framework for teaching) is the most widely used classroom observation tool internationally. His study further confirms the correlation between scores of teaching effectiveness measured by FFT and students' academic performance. It is suggested that teaching administrators should use the cumulative scores of each dimension of FFT as the basis for measuring the effectiveness of teaching, thus providing convenience for teaching evaluation.

In summary, both of the research carried out by Shu Dingfang and the practical operational framework developed by Danielson's team, they all mention the connection between classroom teaching, extracurricular learning and the teaching responsibility of teachers to promote students' ability to develop academically", which is beyond the scope of traditional classroom teaching evaluation in a certain sense.

However, as for the evaluation of foreign language teaching in the era of information age, the author believes that the framework remains to be further improved. Firstly, with the advancement of IT, the application of the information technology and internet resources is becoming more and more popular in the field of language teaching. Scholars need to broaden the connotation of "classroom teaching evaluation" further, because it is not only conducted in a specific classroom teaching evaluation. The involvement of big data and the enhancement of the information literacy of the teachers and students have made it difficult to distinguish the classroom and extracurricular learning in teaching. Hence it is quite necessary to increase the evaluation on the factors affecting the teaching outside the classroom greatly and the ability to guide students o how to use the information and resources provided. Secondly, one of the traditional research domains of the second language acquisition is concerned about the impact of environmental differences on acquisition and learning effect, the most typical one is the differentiation between Learning and acquisition according to the different environments (Krashen, 1981). Therefore, the discussion on the teaching effectiveness evaluation of foreign language education must be in accordance with the social situation of language learning and the era of IT.

The author believes that Mr.Shu's evaluation framework, which is proposed specifically for the foreign language classroom evaluation, however, fails to reflect the differences in the dimension of language teaching. And it can also serve as a general guiding evaluation framework on other courses. While the Danielson's framework, which is primarily designed for new teachers' evaluation of the American Federation of Teachers, does not consider the specific situation of foreign language teaching outside the U.S. Therefore, it is necessary to increase the distinctive and unique second language dimension and the evaluation perspectives of foreign language teaching based on the combination of the research achievements of second language acquisition and foreign language teaching research in China. Based on the considerations above, the author tries to put forward the evaluation framework of foreign language teaching effectiveness by analyzing the typical characteristics of foreign language teaching in the era of IT.

\section{RESEARCH DESIGN}

\section{A. Features}

The facilities and resources of the information technology have affected every aspects of global higher education. these trends and technology is no longer auxiliary tools and external environment for foreign language learning, it has been integrated into the foreign language curriculum and become an indispensable part of foreign language learning(Chen, 2014) this integration produces a new discipline--the foreign language educational technology, which combines the (Hu; Chen, 2013).

To a great extent, the information resource, presented in the form of big data with dual attributes, has changed the mode of language learning and reshaped the language teaching behavior and even contributed to the new teaching mode of cognition. 
While It must be noted that information technology facilities and resources have brought opportunities as well as new challenges to college foreign language teaching. Chen Jianlin (2014) believes that the biggest challenge in foreign language teaching based on big data is to change the way people think while using and analyzing the data, which is manifested in three aspects: random sampling is no longer dependent; The pursuit of accuracy is no longer the main objective; relationship of the cause and effect is no longer clear. Meanwhile, the informatization has also brought new opportunities for foreign language education. Such as: the possibility of personalized learning; the practice of the student-centered conception; the possibility of new curriculum design and blended teaching model; the promotion of teachers' professional development and team building.

Therefore, it has become urgent to study the influence on foreign language teaching brought by the information technology facilities and resources. It is also quite impeditive to promote the integration of information technology and foreign language curriculum and optimize the use of ubiquitous information resources in foreign language teaching in the information age.

\section{B. Measures and Propositions}

As early as the end of twentieth Century, the U.S. government is aware of the trend that social information has a strong influence on education. The Clinton administration in September 1993 formally proposed the construction of "national information infrastructure" (referred to NII), commonly known as the "information superhighway" project. Its core is to develop Internet as the core of the integrated information service system and promote information technology (IT) to be widely used in various fields, especially in education. Subsequently, the concept of educational informatization emerged; major countries in the world attach great importance to construction of education information (Liu, 2014).

China has put forward the policies and regulations for all levels of educational informatization. Such as the Ministry of Education in China issued the notice in 2000, which aimed to promote information technology education in the elementary and middle schools, etc. in recent years, China is gradually shifting from the focus on the construction of educational information infrastructure to the educational information software resources.

The teaching requirements of College English course clearly points out that "all colleges and universities should make full use of modern information technology and adopt the English teaching mode based on computer-assisted classroom teaching and improve the single teaching mode based on Teachers; instruction". The outline of the National Medium-and Long-Term Education Reform and Development Program clearly points out the need to speed up the construction of educational information infrastructure and strengthen the development and application of high quality educational resources.

The Chinese Ministry of Education has issued a Ten-year Outline for the IT Development in Higher Education. In Chapter 6, it says: "the organization involved should work hard to promote the deep integration of information technology with higher education and reform the talent training mode"(DHEMOE, 2007). In the outline, four specific requirements are listed, they are: to strengthen the construction and the application of digital university campus; To promote the innovation of talent training mode; to improve the level of scientific research in colleges and universities; to enhance the ability of social services and cultural heritage in colleges and universities.

In 2020-year National Plan of Education, it also outlines the development framework and its main dimensions of higher education informatization as an important basis for education evaluation.

It can be seen that the development of information and communication technology since the 21 st century has caused the upsurge of educational informatization and the revolution in the teaching of various subjects, such as foreign language education (Jiao, 2008). Education informatization is affecting all aspects of education in an irresistible way. The relevant departments of the state are expected to complete the top-level design scientifically and formulate the corresponding policies. The academic circles are expected to serve for the foreign language education policy-making and modify the outdated teaching mode by generalizing the influence of the information age on foreign language teaching (Shu, 2014).

As far as the evaluation of foreign language teaching is concerned, the academic circles in China need to transform the reality that the former framework ignores the situation of foreign language learning and the characteristics of the information age (Fang, 2017). Meanwhile, According to the characteristics and the real situation of informationized foreign language teaching in China, the researchers should try to design a teaching evaluation framework with rich connotation, reasonable scientific foundation and strong operational application, so as to assist the foreign language teachers in colleges and universities to take insight into the information technology and ensure the effectiveness of teaching.

\section{The Evaluation Framework of EFL Teaching in the Information Age}

The framework of Danielson (2013) is rich in content and operable; the framework of Shu Dingfang (2014) outlines the aims and objectives of classroom teaching. On the basis of framework above, the author puts forward the "four-dimensional framework of foreign language teaching evaluation in the information age" which combines the social educational situation of foreign language teaching in China with the characteristics of the information age. Evaluation dimensions and observational perspectives are shown in table 2: 
TABLE 2:

EVALUATION FRAMEWORK OF EFL TEACHING IN THE ERA OF IT

\begin{tabular}{|c|c|}
\hline $\begin{array}{l}\text { D1: Planning and preparation } \\
\text { 1a. Social and educational awareness; } \\
\text { 1b.Knowledge of learners' characteristics and learning needs; } \\
\text { 1c.Degree of correlation between top-level design and } \\
\text { school-based features; } \\
\text { 1d.The ability to Balance between classroom teaching and } \\
\text { extracurricular autonomous learning; } \\
\text { 1e.The ability to plan the use of teaching facilities and resources ; } \\
\text { 1f.The design capability of multidimensional dynamic } \\
\text { assessment; }\end{array}$ & $\begin{array}{l}\text { D2: Classroom teaching } \\
\text { 2a. The ability to connect classroom teaching with; extracurricular } \\
\text { autonomous learning; } \\
\text { 2b. Awareness and ability to use information facilities and Resources; } \\
\text { 2c. Ability to guide learners' ability to provide service for teaching } \\
\text { with BYOD; } \\
\text { 2d. Ability to reasonably arrange the input and output of EFL; } \\
\text { 2e. Ability of foreign cultural pragmatic penetration; } \\
\text { 2f. Teaching flexibility and sensitivity; }\end{array}$ \\
\hline $\begin{array}{l}\text { D4:Teaching responsibility } \\
\text { 4a. The ability to reflect on teaching; } \\
\text { 4b. Ability to Foster learners' critical thinking; } \\
\text { 4c. Ability to Enlighten learners' data-drive learning; } \\
\text { 4d.The ability to integrate and participate in academic activities; } \\
\text { 4e. The ability to develop academically; } \\
\text { 4f. Information literacy and information ability; }\end{array}$ & $\begin{array}{l}\text { D3: Extension of the second class } \\
\text { 3a. The ability to extend classroom teaching to the second classroom; } \\
\text { 3b. The consciousness and ability to use extracurricular information } \\
\text { resources; } \\
\text { 3c. The ability to guide learners to learn independently after class; } \\
\text { 3d. Ability to Encourage learners to use English outside the } \\
\text { classroom; } \\
\text { 3e. The ability to use the information platforms or communication } \\
\text { terminals to guide learners; } \\
\text { 3f. The ability to arrange the first and second classroom learning; }\end{array}$ \\
\hline
\end{tabular}

As is shown in figure 2, the new framework is presented with a reference to the Danielson's framework. But the 2nd dimension of "classroom environment" is removed from the original framework for two reasons: firstly, it is difficult for teachers to reform the classroom environment which is mostly established in China. Second, the emergence of the information age has extended the traditional classroom teaching to the second classroom, where learning is mainly relying on learners' autonomy and data-driven learning. Based on these considerations, a mere focus on the classroom environment is not enough to effectively evaluate the role of teachers. The "second classroom extension" is added to the new framework as the 3rd dimension, which further reflects the importance of "connection between the classroom teaching and extracurricular learning" in the framework of "Shu Dingfang" (2014). For another, it is consistent with the author's view that "vague boundary between the classroom teaching and extracurricular learning". Besides, in this dimension, the information awareness and behavior of teachers is also under observation, which reflects the emphasis that teachers should use the Internet platform to guide learners in the information age. The abundance of information resources has provided a more sufficient target language input for foreign language learning. However, the learners' language output is still quite limited and teachers are required to encourage them.

In addition, the author adjusts the multiple observational perspectives in Danielson's (2013) framework to the real situation of informatization and China's foreign language teaching. For instance, the first three observational perspectives in the dimension of "planning and preparation" focus on the evaluation of teachers' knowledge about the international, national and school-based environment of foreign language teaching and learning in China as well as the characteristics and needs of learners.

The other three perspectives in this dimension are reflected in the beginning of teaching design. Teachers should fully recognize the potential of information facilities and resources in foreign language teaching and the trend of classroom teaching extension and design a reasonable evaluation method with multiple dimensions to measure the effectiveness of learning. In the 3rd dimension of "classroom teaching", the change of observation angle reflects the focus on the connection between the classroom and extracurricular learning and the efficiency and flexibility of using information facilities and resources.

In the 4th dimension of "teaching responsibility", in order to evaluate the teachers' adaptation to the new demands of the times, the guarantee conditions of the effective teaching are evaluated from the perspectives of teachers' self-reflection, the change of the teachers' conception and teachers' willingness to accept information facilities and resources.

\section{Operational Conception of the New Framework}

Compared with the previous teaching evaluation framework, the new framework proposed in this paper focuses on the characteristics of the present era and assesses the teachers' guidance on the learners' autonomous learning ability and learners' awareness and ability of learning in the second classroom. Compared with Danielson's (2013) framework, the new framework takes the social-educational situation of FLT in China into consideration. The applicability of the framework is clearer and more specific, which is convenient for planning and teaching evaluation design. In particular, we can use multiple ways to put the evaluation framework into practice. Such as: "the qualitative analysis of teaching $\log$ ", "the questionnaire and scale of students' teaching evaluation", "questionnaire of information literacy of teachers and students" and "teachers' participation in students' extracurricular learning activities and interview analysis of the roles of teachers and students in autonomous and data-driven learning". All these research tools can perfectly prove the applicability and reliability of the new framework.

First of all, It can be inferred from the analysis of teaching log how teachers' would understand the characteristics of the information era in various stages of teaching, such as "planning and preparation; classroom teaching and 
extracurricular guidance", etc. The analysis of foreign language learners' log can verify the accuracy of the speculation above. Secondly, we can design the questionnaires by referring to the evaluation dimension and perspective of the new framework, and adopt the Likert scale or the open questionnaire. And through factor analysis and qualitative analysis to define the weight of each dimension, quantitative scores and qualitative results of teaching evaluation can be gained to provide a better backwash role for teaching.

Thirdly, the questionnaire about teachers' information literacy (including information awareness and information ability) and information behavior are designed to provide evidence for measuring the effectiveness of foreign language teaching in the information age. Lastly, based on the research of teacher-student interview and teaching and learning behavior, the studies suggested can expand the connotation of effective classroom teaching by analyzing the roles of teachers in classroom teaching and students' autonomous and data-driven learning.

\section{CONCLUSION}

Educational informatization has overwhelmingly affected every aspect of foreign language teaching. The changes have brought opportunities and convenience to the foreign language teaching as well as challenges for teaching activities and information resources application. How to guide students to make the rational use of facilities and equipment with extreme ease has become a big problem in teaching practice. Teaching evaluation has always been an important means to evaluate the effectiveness of teaching.

In this paper, the author firstly analyzes the characteristics of effective foreign language teaching in the information age, and then the author argues that the research circle should expand the connotation of classroom teaching. In teaching evaluation, attention should be paid to teachers' role in the second classroom and teachers' Consciousness and ability to use the information facilities and resources.

Under the influence of teaching evaluation framework of Danielson (2013) and Shu Dingfang (2014), we propose an evaluation framework for foreign language teaching in information era, which has absorbed the essence of the framework of the two scholars. Considering the characteristics and demands of foreign language teaching in the information age, the new framework includes four dimensions and 24 macro observation perspectives.

However, because empirical research is yet to be carried out, the author fails to put forward a feasible evaluation and questionnaire in the new framework under the guidance of the new framework. In this paper, the feasibility and reliability of the new evaluation framework is yet to be tested in the more operative follow-up research, which may come up with more convincing data and feedback to the EFL classroom teaching, thus improving the overall effectiveness of EFL teaching in China.

\section{APPENDIX. ABBREVIATIONS}

1, EFL, English as a Foreign Language

2, IT, Information Technology

3, CALL, Computer-assisted Language Learning

4, FFT, Framework for Teaching

5, 2020-NPE, 2020-year National Plan for Education

6, BOCEC, the Basic Outlines of College English Course

7, DHEMOE, Department of Higher Education in Ministry of Education

\section{REFERENCES}

[1] Bachman, L. F. (1996). Language Testing in Practice. Oxford: Oxford University Press.

[2] Bachman, L. F. (2010). Language Assessment in Practice. Oxford: Oxford University Press.

[3] Chen Jianjin. (2010). Integration of Computer Network and Foreign Language Curriculum: A Study Based on College English Teaching Reform. Shanghai: Shanghai Foreign Language Education Press.

[4] Chen Jianlin. (2014). The study of MOOCS and foreign language teaching in the era of big data -Challenges and opportunities. Audio-visual Foreign Language Teaching 93.1, 27-36.

[5] Dai Weidong. (2008). Emancipating the mind and seeking truth from facts and promote the development of Foreign language Education in China. Foreign language world 92.4, 24-29.

[6] Danielson, C. (2013). The Framework for Teaching Evaluation Instrument. http://danielsongroup.org. (accessed 10/1/2017)

[7] David, Hawkridge. (2008). User-centered design of online learning communities. British Journal of Educational Technology 39.3, 103-118.

[8] Department of Higher Education in Ministry of education. (2007). Basic Outlines of College English Teaching. Shanghai: Shanghai Foreign language Education Press.

[9] Graves, K. (2008). The language curriculum: a social contextual perspective. Language Teaching 23.3, 36-48.

[10] Garrett, M. (2015). Examining teacher effectiveness by using classroom observation scores: Evidence from the randomization of teachers to students. Educational Evaluation and Policy Analysis 13.4, 103-116.

[11] Hu Jiasheng, Chen Jianlin. (2013). An outline of foreign language educational technology. Audio-visual Foreign Language Teaching 87.6, 29-36. 
[12] Harris, D. N., Ingle, W. K. (2014). How teacher evaluation methods matter for accountability: A comparative analysis of teacher effectiveness ratings by principals and teacher value-added measures. American. Educational Research Journal 36.2, 36-53.

[13] Jiao Jianli. (2008). Research on the integration of Internet into middle school English Teaching. http://www.jiaojianli.com/391.html. (accessed 23/1/2017).

[14] Johnson, K, A. (1989). Decision-making Framework for the Coherent Language Curriculum. In Johnson, K(ed). The Second Language Curriculum. Cambridge: Cambridge University Press.

[15] Krashen, S. (1981). Second Language Acquisition and Second Language Learning. Oxford: Pergamon.

[16] Liu Xian. (2014). Research on the development strategy of infrastructure in the process of educational Informatization. Journal of Distance Education 86.2, 19-26.

[17] Mark Warschauer. (2000). Internet for English teaching: Teachers of English to speakers of other languages. TESOL 23.3, 28-35.

[18] Michael, Levy. (1997). Computer Assisted Language Learning: Context and Conceptualization. Cambridge: Cambridge University Press.

[19] Michael, Thomas. (2009). Handbook of Research on Web 2.0 and Second Language Learning. IGI Global.

[20] Mei Ping. (2013). Review on the effectiveness of college students' evaluation of teaching in recent ten years. Modern Education of University 67.8, 16-25.

[21] Nunan, D. (1988). Syllabus Design. Oxford: Oxford University Press.

[22] Richards, J. (1990). The language Teaching Matrix. Cambridge: Cambridge University Press

[23] Shao Yingiiao. (2015). Literature review of college students' evaluation of teaching in China. Education Review 56.4, 58-65.

[24] Shu Dingfang. (2010). What do we teach and how do we teach in College English classroom? Foreign Language World 63.5, 28-35.

[25] Shu Dingfang. (2014). On the problems and some research subjects in EFL teaching. Foreign language Teaching and Research 89.3, 35-41.

[26] Wang Chuanying. (2012). Needs analysis of language service in international trade companies and enlightenment in 2011.Chinese Translation 53.8, 54-61.

[27] Wang Xuemei. (2002). Reflection on the postgraduate education of English majors in China from the perspective of the needs analysis of academic ability. Foreign Language World 55.9, 36-45.

[28] Wen Qiufang. (2014). Dynamic characteristics and methods of goal in the Instant formative Assessment of Foreign language classroom. Foreign language Teaching and Research 75.3, 38-45.

[29] Xia Jimei. English teachers' knowledge and ability in foreign language education. Foreign language World 46.2, 59-75.

Jinzhu Zhang, Male, lecturer at School of Foreign Languages of Tianjin Polytechnic University, Tianjin, China. His research interest lies in the Applied Linguistics and Language Testing Theory \& Practice. 